\title{
Impact of Momordica Charantia (Karela) on the Proportion of Hepatocytes with Intranuclear Inclusions in the Streptozotocin- Induced Diabetic Rats
}

\author{
Mohal S ${ }^{1}$, Hossain $\mathrm{MA}^{2}$, Mondal DK³ , Ara S4, Shamim KM ${ }^{5}$
}

\begin{abstract}
Background: Momordica charantia has some hypoglycemic properties. Objective: The purpose of the present study was to find out the impact of Momordica charantia (karela) on the proportion of hepatocytes in the Streptozotocin-induced diabetic rats. Methodology: This was an animal study carried out in the Department of Anatomy at Bangabandhu Sheikh Mujib Medical University (BSMMU) and Bangladesh Institute of Research \& rehabilitation in Diabetes, Endocrine \& metabolic Disorders (BIRDEM), Dhaka. Healthy young Long Evans rats of male sex weighing 150 to $280 \mathrm{gm}$ with an age range of 10 to 12 weeks were used in this study. The rats were divided into 4 equal groups depending upon their different sorts of dietary feedings and drug treatment. The variation of different proportion of hepatocytes with intranuclear inclusions in different groups of rat was monitored. Result: Sixty five rats were included in this study. Mean proportion of hepatocytes with intranuclear inclusions on day 51 from Streptozotocin/vehicle injection in the control group which was known as Group-A was 0 . In untreated diabetic group the mean proportion of hepatocytes with intranuclear inclusions was $3.71 \pm 0.82$. On the other hand, in the insulin-treated diabetic rats the mean proportion of hepatocytes with intranuclear inclusions was 0 and in the karela-treated diabetic rats, the proportion of hepatocytes with intranuclear inclusions was 0 . The value in the insulin-treated diabetic rats $(\mathrm{p}=0.0001)$ and in the karela-treated diabetic rats $(\mathrm{p}=0.0001)$ were significantly lower than that of the untreated diabetic rats; however, there was no significant difference between the insulin-treated diabetic rats \& the karela-treated diabetic rats $(\mathrm{P}>0.05)$ in this regard. Conclusion: Karela showed a tendency of acting against hyperglycemic effects of Streptozotocin-induced diabetes mellitus and also acting against the rise in proportion of hepatocytes with intranuclear inclusions in Streptozotocin-induced diabetes mellitus. [ J Shaheed Suhrawardy Med Coll, 2013;5(2):84-86]
\end{abstract}

Keywords: Diabetes mellitus, hyperglycemia, hepatocytes with intranuclear inclusions, momordica charantia, karela

Received: May 2013; Revised: June 2013; Accepted: September 2013

\section{Introduction}

Diabetes mellitus is major health problem in the years together'. In Bangladesh a high proportion of diabetics are registered to different clinic and institutes, among which only Bangladesh Institute of Research and Rehabilitation in diabetes, Endocrine \& Metabolic Disorders (BIRDEM), Dhaka. Although it is understandable that many of the diabetic patient especially in the rural area have not registered themselves to any diabetic clinic or hospitals and many other still remain undiagnosed ${ }^{2}$.

In the treatment of diabetes mellitus synthetic oral hypoglycaemics have various site effects and contraindications which have led to scientists to search for alternatives and many natural products indigenous to various parts of the world ${ }^{3}$. A large number of herbal products have

1. Prof. Dr. Shirin Mohal, Professor Department of Anatomy, Z.H. Sikder Women's Medical College, Dhaka

2. Dr. Md.Afzal Hossain, Associate Professor, Department of Microbiology, Z.H.Sikder Women's Medical College, Dhaka

3. Prof. Dr. Dulal Krishna Mondal, Professor and Head, Department of Anatomy, Diabetic Association Medical College, Faridpur

4. Prof. Dr. Shamim Ara, Professor, Department of Anatomy, Dhaka Medical College, Dhaka

5. Dr. Khandaker Manzare Shamim, Professor, Department of Anatomy, Banghabandhu Sheik Mujib Medical University, Dhaka

Correspondence

Prof. Dr. Shirin Mohal, Professor, Department of Anatomy, Z.H. Sikder Women's Medical College, Dhaka, Bangladesh; Email: shirin40@yahoo.com; Cell no.: +8801677552484

Conflict of interest: None

Financial Support: None

Contributions by authors: SM, DKM, SAE \& KMS were involved in the protocol preparation to data analysis \& data collection; SM, MAH Prepared the manuscript \& revised it. 
been used as remedies of polyurea ${ }^{2}$. Some of these are in the usual food list of the people concerned. Scientific studies also revealed the hypoglycaemic properties in many of these herbal products ${ }^{3}$. Among these herbal products Momordica charantia ('karela' or bitter ground) is one of such natural products which were cultivated in the many parts of Africa, South America as well as Asia.

Diabetes mellitus causes rise in the proportion of hepatocytes with intranuclear inclusions. This may indicate that 'karela' has antidiabetic role. This may also be used to minimize the rise in the proportion of hepatocytes with intranuclear inclusions in Streptozotocin-induced diabetes mellitus. The purpose of the present study was to find out the impact of Momordica charantia (karela) on the proportion of hepatocytes in the Streptozotocin-induced diabetic rats.

\section{Methodology}

This experiment was carried out on a total number of 65 young rats of male long Evans strain. They were 10 to 12 wks old, weighing between 150 and $280 \mathrm{gm}$. Among them 10 rats were treated with vehicle (citrate buffer solution $1 \mathrm{ml} / \mathrm{kg}$ body weight intraperitoneally) only used as control rats (Group A) and 45 rats were treated with vehicle and Streptozotocin found as diabetes, 15 of which were treated as untreated diabetic control group (Group B), 15 were treated again with insulin at a dose of 1 - 3 units/ $\mathrm{kg}$ body weight / day, were treated as the insulin-treated diabetic group (Group C) and 15 were treated with karela at a dose of $10 \mathrm{ml} / \mathrm{kg}$ body weight / per day orally through tube to control the diabetes mellitus and was called as 'karela'- treated diabetic group (Group D). In the Research Division of BIRDEM, Dhaka, the proportion of hepatocytes with intranuclear inclusions (per square $\mathrm{mm}$ ) of liver section of all the rats, was estimated by a square on the slides which was standardized in such a way with a stage micrometer that it represented an area of 10,000 $\mu \mathrm{m}^{2}$ in the tissue section under X100 oil immersion objective.

\section{Results}

The proportion of hepatocytes with intranuclear inclusions was estimated in all rats on day 51 from day of STZ/vehicle injection (Table 1). The proportion of hepatocytes with intranuclear inclusions was estimated in (per square $\mathrm{mm}$ ) of liver section of all the rats. In control group the mean hepatocytes with intranuclear inclusions was $0 \pm 0$. In untreated diabetic group the mean hepatocytes with intranuclear inclusions was $3.71 \pm 0.82$. In insulin-treated diabetic rats the mean hepatocytes with intranuclear inclusions was $0 \pm 0$. On the other hand, in the karela-treated diabetic rats the mean hepatocytes with intranuclear inclusions was $0 \pm$ 0 . Statistical analyses also showed that the hepatocytes with intranuclear inclusions on day 51 from STZ injection were significantly lower in each of those two group, Group $C$ \& Group D, than in the untreated diabetic (Group B) $(p=0.0001$ and $p=0.0001)$ respectively. However, there was no significant different between these two groups $(\mathrm{p}>0.05)$ in this regard.
Table 1: Proportion of Hepatocytes with Intranuclear Inclusions in Different Groups of Rats

\begin{tabular}{lc}
\hline Group & $\begin{array}{c}\text { Hepatocytes with } \\
\text { Intranuclear Inclusions } \\
\text { (Mean } \pm \text { SD) }\end{array}$ \\
\hline Group A (Control) & 0 \\
Group B (Untreated Diabetic) & $3.71 \pm 0.82$ \\
Group C (Insulin-treated diabetic) & 0 \\
Group D ('Karela'-treated diabetic) & 0 \\
\hline
\end{tabular}

* Statistical analyses for significance of differences between different groups through Student 't' test. Group B vs A: $\mathrm{P}=0.0001$; group C vs B : $\mathrm{P}=0.0001$; group $\mathrm{D}$ vs $\mathrm{B}: \mathrm{P}=0.0001$; group $\mathrm{C}$ vs $\mathrm{D}: \mathrm{P}>0.05$

\section{Discussion}

Karela is very popular as a vegetable in Bangladesh. In Sri-Lanka the fruit juice of M. charantia is considered as an effective hypoglycemic agent in management of diabetes mellitus ${ }^{4}$. In the other parts of the world it is used as the folk medicine to the treatment of diabetes ${ }^{1}$. 'Karela's hypoglycemic property has also been shown experimentally in the diabetics as well as in normal laboratory animals ${ }^{5}$.

Momordica charantia Linn. (Karela) commonly known as bitter melon or bitter gourd is tropical and subtropical climber of the family Cucurbitaceae. It is widely distributed in China, Malaysia, India and tropical Africa. The Latin name Momordica means "to bite" (referring to the jagged edges of the leaf, which appear as if they have been bitten). All parts of the plant, including the fruit taste very bitter ${ }^{1}$, as it contains a bitter compound called momordicin that is believed to have a stomachic effect ${ }^{2}$. In Ayurveda, various parts of Momordica charantia (Karela) are recommended for many diseases like; cholera, bronchitis, anemia, blood diseases, ulcer, diarrhea, dysentery, sexual tonic and as a cure for gonorrhea ${ }^{3}$. Karela contains an array of biologically active plant chemicals including triterpens, proteins, steroids, alkaloids, saponins, flavonoids and acids due to which plant possesses anti-fungal, anti-bacterial, anti-parasitic, anti-viral, anti-fertility, anti-tumor, hypoglycemic and anticarcinogenic properties ${ }^{4-8}$. Fruits are used as traditional medication to cure various diseases like rheumatism, gout, worms, colic, disease of liver and spleen ${ }^{9}$. It is also found useful in the treatment of cancer and diabetes ${ }^{10}$. It is a potent hypoglycemic agent due to alkaloids and insulin like peptides and a mixture of steroidal sapogenins known as charantin ${ }^{11}$.

Untreated diabetic rats showed the significant higher hepatocytes with intranuclear inclusions than the control rats. Enlargement of the hepatocytes with intranuclear inclusions along with higher hepatocytes with intranuclear inclusions has been found to be a feature of experimentally induced diabetic rats ${ }^{6}$.

The hepatocytes with intranuclear inclusions decrease by the treatment with Momordica charantia (karela) of all the diabetic rats. The hepatocytes with intranuclear inclusions in insulin-treated and karela-treated diabetic rats were 
significantly lower than that in the untreated diabetic rats. This impact was similar to that of the effect of insulin on STZ - induced diabetic rats ${ }^{1}$. Similar findings were also observed by another study ${ }^{6}$. Doi et $\mathrm{al}^{3}$ found the higher hepatocytes with intranuclear inclusions in STZ induced diabetic rats than that in the control mice. In case of diabetes mellitus hepatocytes with intranuclear inclusions are increased and thus hepatocytes with intranuclear inclusions may be an important landmark to detect the diabetic status ${ }^{6-7}$.

\section{Conclusion}

Momordica charantia (karela) showed a tendency of lowering the higher proportion of hepatocytes with intranuclear inclusions in diabetes mellitus. However further investigations are recommended for establishing the active ingredient(s) of karela as a safe, useful and effective hepatocytes with intranuclear inclusions-lowering agent in diabetes mellitus as well as the anti-hyperglycaemic agent.

\section{Acknowledgement}

I would like to express my heartfelt gratitude to my respected teacher Prof. M. A. Hai Fakir, former Head, Dept. of Anatomy and Professor Dr. Harun-Ar-Rashid, former Head, Dept. of Anatomy, IPGMR (at present BSMMU), Dhaka. Dr. Liaquat Ali, Professor of Biochemistry, BIRDEM and Dr. Begum Rokya, Professor, Pharmacology, BIRDEM for their valuable suggestions during my study period.

\section{References}

1. Tennekoon KH, Jeevathayapuran S, Angunawala P, Karunanayake EH, Jahyasinghe KSA. Effect of Momordica charantia on key hepatic enzyme. J Ethnopharm 1994; 44: 93-7
2. Caqkici I, Hurmoglu C, Tunctan B, Abaacioglu N, KanziK I, Sener B. Hypoglycemic effect of Momordica charantia extracts in normoglycaemic or cyproheptadine-induced hypoglycaemic mice. J Ethnopharm 1994; 44: 117-21 3. Doi K, Yamanouchi J, Kume E, Yasostilma A. Morphologic changes in hepatocyte muclei of streptozotocin (SZ)- induced diabetic mice. J Expl Toxic Pathol 1997; 49:295-9

4. Karunanayake EH, Jeevathayaparan S, Tennekoon KH. Effect of Momordica charantia fruit juice on streptozotocin-induced diabetes in rats. J Ethnopharm 1990; 30: 199-204

5. Karunanayake EH, Welihinda J, Sirimanne SR. Sinadorai G. Oral hypoglycaemic activity of some medicinal plants of Sri Lanka.

J Ethnopharm 1984; 11: 223-31

6. Welihida J, Arvidson G, Gylfe E, Hellman B, Karlsson E. The insulin releasing activity of the karela. Biochem pharmacol 2001;58:1820-23

7. Day C, Cartwrit T, ProvostJ, Bailey C. Hypoglycaemic effect of Momordica charantia extracts. Dept of Pharmace Sci Biol Div, Aston Univ, UK. 1990: 426-9

8. Ali L, Khan AKA, Mamun MIR, Mossiuzzaman M, Nahar N, Nur-eAlam $\mathrm{M}$ et al. Studies in hypoglglycaemic effects of fruit pulp, seed and whole plant of Momordica charantia on normal and diabetic rats. Plant Med 1993; 59: 408-12

9. Raza H, Ahmed J, Lakhani MS, Sharma AK, Pallot D, Montaque W. Effect of bitter malon (Momordica charantia) frut juice on the hepatic cytochrome P45-dependent monoxygenases and glutathione S-transferases in streptozotocin-induced diabeticd rats. Biochem pharmacol 1996; 52: 1639-42 10. Welihida J, Karunanayake EH. Extra-pancreatic effect of Momordica charantia in rats. J Ethnopharm 1986; 17: 247-55

11. Ahmed I, Lakhani MS, Gillett M, John A, Raza H. Hypotriglyceridemic and hypocholesterolemic effects of anti-diabetic Momordica charantia (karela) fruit extract in streptozotocin-induced diabetic rats. Diabetes research and clinical practice. 2001;51(3):155-61 